\title{
Linear Incidence Edge Prime Labeling - More Results on Path Related Di Graphs
}

\author{
Sunoj B.S.*,1 and Mathew Varkey T.K. ${ }^{2}$ \\ 1Department of Mathematics, Government Polytechnic College, Attingal, Kerala, India \\ 2Department of Mathematics, TKM College of Engineering, Kollam, Kerala, India
}

\begin{abstract}
Article Type: Article
Article Citation: Sunoj BS, Mathew Varkey TK. Linear incidence edge prime labeling - more results on path related di graphs. Indian Journal of Science and Technology. 2020; 13(02), 141-148. D0l: 10.17485/ijst/2020/ v013i02/148783
\end{abstract}

Received date: November 10, 2019 Accepted date: December 5, 2019

*Author for correspondence: B.S. Sunoj spalazhi@yahoo. com 9 Department of Mathematics, Government Polytechnic College, Attingal, Kerala, Indiax

\begin{abstract}
Objectives: Our aim is to find new families of di graphs that admit linear incidence edge prime labeling. Methods/statistical analysis: Here the vertices are assigned with $0,1, \ldots, m-1$ and edges with $2 g(v)$ $+g(u)$, where $u$ is the initial vertex and $v$ is the terminal vertex and $g$ is the vertex labeling function. The graph is prime when the greatest common incidence number of vertices with in degree greater than one is one. Findings: Here we prove that di graph of corona product of $\mathrm{P}_{\mathrm{n}}$ with $\mathrm{K}_{2}$, strong shadow graph of path $\mathrm{P}_{\mathrm{n}}$, strong splitting graph of path $P_{n}$, square graph of path $P_{n}$, tortoise graph of path $P_{n}$ graph obtained by joining the corresponding internal vertices of two copies of path $P_{n}$, strong $Z$ graph of path $P_{n}$ admit linear incidence edge prime labeling. Application/improvements: One can generalize these results and find some structural properties. These results may be applied to the transportation problem, chemical graph theory and decision analysis.
\end{abstract}

Keywords: Linear, Incidence, Prime Labeling, Strong Z Graph of Path $P_{n}$, Strong Shadow Graph of Path $P_{n}$, Strong Splitting Graph of Path $P_{n}$.

\section{Introduction}

Here all di graphs are finite and connected. Each edge of graph $\mathrm{G}$ is assigned a direction from the vertex $v$ to the vertex $u$ iff the vertex label of $v$ is less than the vertex label of $u$. Here we label the vertices with the numbers $0,1, \ldots, m-1$. The edges are labeled with $2 \mathrm{~g}(\mathrm{v})$ $+\mathrm{g}(\mathrm{u})$, where $\mathrm{u}$ is the initial vertex and $\mathrm{v}$ is the terminal vertex and $\mathrm{g}$ is the vertex labeling function. In [6], we introduced the linear incidence edge prime labeling of di graphs. We use some results, definitions, and notations from [1-6]. In this paper, we investigate linear incidence edge prime labeling of some families of path related di graphs.

Definition 1.1 The greatest common incidence number (gcin) of a vertex of in degree greater than or equal to 2 is the greatest common divisor (gcd) of the labels of the edges incident on that vertex. 
Definition 1.2 If each edge of a graph has a direction, then that graph is called a di graph.

Definition 1.3 Number of edges incident on a vertex of a di graph is called the in the degree of that vertex.

\section{Main Results}

Definition 2.1 Let $G$ be a graph with m vertices and n edges. Define a relation g: $V(G) \rightarrow$ $\{0,1,2, \ldots, \mathrm{m}-1\}$ by $\mathrm{g}\left(\mathrm{u}_{\mathrm{j}}\right)=\mathrm{j}-1$, for every $\mathrm{j}$ from 1 to $\mathrm{m}$ and define a relation $g_{\text {liepl }}^{*}: \mathrm{E}(\mathrm{G})$ $\rightarrow$ set of natural numbers $\mathrm{N}$ by $g_{\text {liepl }}^{*}\left(u_{i} u_{j}\right)=g\left(u_{i}\right)+2 g\left(u_{j}\right)$ for every direct edge $\mathrm{u}_{\mathrm{i}} \mathrm{u}_{\mathrm{j}}$. $\mathrm{G}$ is a linear incidence edge prime graph if it satisfies the following 3 conditions.

1. $\mathrm{g}$ is $1-1$ and onto.

2. $g_{\text {liepl }}^{*}$ is $1-1$.

3. gcin of each vertex of in degree greater than or equal to 2 is one.

Theorem 2.1 Direct graph of $\mathrm{P}_{m} \theta \mathrm{K}_{2}(\mathrm{~m}>2)$ is a linear incidence edge prime graph.

Proof: Let $G^{\rightarrow}$ be the di graph and $\mathrm{u}_{1}, \mathrm{u}_{2}, \ldots, \mathrm{u}_{3 \mathrm{~m}}$ are the vertices of $G^{\rightarrow}$

Here $\left|\mathrm{V}\left(G^{\rightarrow}\right)\right|=3 \mathrm{~m}$ and $\left|\mathrm{E}\left(G^{\rightarrow}\right)\right|=4 \mathrm{~m}-1$.

Define a relation $\mathrm{g}: \mathrm{V} \rightarrow\{0,1,2, \ldots, 3 \mathrm{~m}-1\}$ by

$g\left(u_{j}\right)=j-1, \quad j=1,2, \ldots, 3 m$

It is evident from the definition that $\mathrm{g}$ is a $1-1$ and onto mapping.

Edge labeling $g_{\text {liepl }}^{*}$ is defined as:

$$
\begin{array}{lll}
g_{\text {liepl }}^{*}\left(u_{3 j-2} u_{3 j-1}\right) & =9 \mathrm{j}-7, & \mathrm{j}=1,2, \ldots, \mathrm{m} . \\
g_{\text {liepl }}^{*}\left(u_{3 j-2} u_{3 j}\right) & =9 \mathrm{j}-5, & \mathrm{j}=1,2, \ldots, \mathrm{m} . \\
g_{\text {liepl }}^{*}\left(u_{3 i-1} u_{3 i}\right) & =9 \mathrm{j}-4, & \mathrm{j}=1,2, \ldots, \mathrm{m} . \\
g_{\text {liepl }}^{*}\left(u_{3 i-2} u_{3 i+1}\right) & =9 \mathrm{j}-3, & \mathrm{j}=1,2, \ldots, \mathrm{m}-1 .
\end{array}
$$

Clearly $g_{\text {liepl }}^{*}$ is a one-one mapping.

$$
\begin{aligned}
\operatorname{gcin} \text { of }\left(\mathrm{u}_{3 \mathrm{j}}\right) & =\operatorname{gcd} \text { of }\left\{g_{\text {liepl }}^{*}\left(u_{3 j-2} u_{3 j}\right), g_{\text {liepl }}^{*}\left(u_{3 j-1} u_{3 j}\right)\right\} \\
& =\operatorname{gcd} \text { of }\{9 \mathrm{j}-5,9 \mathrm{j}-4\} \\
& =1, \quad \mathrm{j}=1,2, \ldots, \mathrm{m} .
\end{aligned}
$$

Hence, $P_{m} \theta K_{2}$ is a linear incidence edge prime graph.

Theorem 2.2 Direct strong shadow graph of path $\mathrm{P}_{\mathrm{m}}(\mathrm{m}>2)$ is a linear incidence edge prime graph. 
Proof: Let $G \rightarrow$ be the di graph and $\mathrm{u}_{1}, \mathrm{u}_{2}, \ldots, \mathrm{u}_{2 \mathrm{~m}}$ are the vertices of $G^{\rightarrow}$

Here $\left|\mathrm{V}\left(G^{\rightarrow}\right)\right|=2 \mathrm{~m}$ and $\left|\mathrm{E}\left(G^{\rightarrow}\right)\right|=5 \mathrm{~m}-4$.

Define a relation $\mathrm{g}: \mathrm{V} \rightarrow\{0,1,2, \ldots, 2 \mathrm{~m}-1\}$ by

$$
g\left(u_{j}\right) \quad=j-1, \quad j=1,2, \ldots, 2 m
$$

It is evident from the definition that $\mathrm{g}$ is a $1-1$ and onto mapping.

The edge labeling $g_{\text {liepl }}^{*}$ is defined as follows:

$$
\begin{array}{lll}
g_{\text {liepl }}^{*}\left(u_{2 j-1} u_{2 j}\right) & =6 \mathrm{j}-4, & \mathrm{j}=1,2, \ldots, \mathrm{m} . \\
g_{\text {liepl }}^{*}\left(u_{2 j-1} u_{2 j+1}\right) & =6 \mathrm{j}-2, & \mathrm{j}=1,2, \ldots, \mathrm{m}-1 . \\
g_{\text {liepl }}^{*}\left(u_{2 j} u_{2 j+1}\right) & =6 \mathrm{j}-1, & \mathrm{j}=1,2, \ldots, \mathrm{m}-1 . \\
g_{\text {liepl }}^{*}\left(u_{2 j-1} u_{2 j+2}\right) & =6 \mathrm{j}, & \mathrm{j}=1,2, \ldots, \mathrm{m}-1 . \\
g_{\text {liepl }}^{*}\left(u_{2 j} u_{2 j+2}\right) & =6 \mathrm{j}+1, & \mathrm{j}=1,2, \ldots, \mathrm{m}-1 .
\end{array}
$$

Clearly $g_{\text {liepl }}^{*}$ is an injection.

$$
\begin{aligned}
\operatorname{gcin} \text { of }\left(\mathrm{u}_{2 \mathrm{i}+1}\right) & =\operatorname{gcd} \text { of }\left\{g_{\text {liepl }}^{*}\left(u_{2 j-1} u_{2 j+1}\right), g_{\text {liepl }}^{*}\left(u_{2 j} u_{2 j+1}\right)\right\} \\
& =\operatorname{gcd} \text { of }\{6 \mathrm{j}-2,6 \mathrm{j}-1\} \\
& =1, \quad \mathrm{j}=1,2, \ldots, \mathrm{m}-1 . \\
\operatorname{gcin} \text { of }\left(\mathrm{u}_{2 \mathrm{i}+2}\right) & =\operatorname{gcd} \text { of }\left\{f_{l p l}^{*}\left(u_{2 j-1} u_{2 j+2}\right), f_{l p l}^{*}\left(u_{2 j} u_{2 j+2}\right)\right\} \\
& =\operatorname{gcd} \text { of }\{6 \mathrm{j}, 6 \mathrm{j}+1\} \quad \quad \mathrm{j}=1,2, \ldots, \mathrm{m}-1 .
\end{aligned}
$$

Hence $S\left\{D_{2}\left(P_{n}\right)\right\}$, is linear incidence edge prime graph.

Theorem 2.3 Direct strong splitting graph of path $\mathrm{P}_{\mathrm{m}}(\mathrm{m}>2)$, is a linear incidence edge prime graph.

Proof: Let $\quad \rightarrow$ be the di graph and $\mathrm{u}_{1}, \mathrm{u}_{2}, \ldots, \mathrm{u}_{2 \mathrm{~m}}$ are the vertices of $G \rightarrow$.

Here $\left|\mathrm{V}\left(G^{\rightarrow}\right)\right|=2 \mathrm{~m}$ and $\left|\mathrm{E}\left(G^{\rightarrow}\right)\right|=4 \mathrm{~m}-3$.

Define a relation $\mathrm{g}: \mathrm{V} \rightarrow\{0,1,2, \ldots, 2 \mathrm{~m}-1\}$ by

$$
g\left(u_{j}\right) \quad=j-1, \quad j=1,2, \ldots, 2 m .
$$

It is evident from the definition that $\mathrm{g}$ is a $1-1$ and onto mapping.

The edge labeling $g_{\text {liepl }}^{*}$ is defined as follows: 


$$
\begin{array}{lll}
g_{\text {liepl }}^{*}\left(u_{2 j-1} u_{2 j}\right) & =6 \mathrm{j}-4, & \mathrm{j}=1,2, \ldots, \mathrm{m} . \\
g_{\text {liepl }}^{*}\left(u_{2 j} u_{2 j+1}\right) & =6 \mathrm{j}-1, & \mathrm{j}=1,2, \ldots, \mathrm{m}-1 . \\
g_{\text {liepl }}^{*}\left(u_{2 j-1} u_{2 j+2}\right) & =6 \mathrm{j}, & \mathrm{j}=1,2, \ldots, \mathrm{m}-1 . \\
g_{\text {liepl }}^{*}\left(u_{2 j} u_{2 j+2}\right) & =6 \mathrm{j}+1, & \mathrm{j}=1,2, \ldots, \mathrm{m}-1 .
\end{array}
$$

Clearly $g_{\text {liepl }}^{*}$ is a one-one mapping.

$$
\begin{aligned}
& \text { gcin of }\left(\mathrm{u}_{2 j+2}\right) \\
& =\operatorname{gcd} \text { of }\left\{g_{\text {liepl }}^{*}\left(u_{2 j-1} u_{2 j+2}\right), g_{\text {liepl }}^{*}\left(u_{2 j} u_{2 j+2}\right)\right\} \\
& =\operatorname{gcd} \text { of }\{6 \mathrm{j}, 6 \mathrm{j}+1\} \\
& =1 \text {, } \\
& \mathrm{j}=1,2, \ldots, \mathrm{m}-1 \text {. }
\end{aligned}
$$

Hence $S\left\{S,\left(P_{n}\right)\right\}$, is a linear incidence edge prime graph.

Theorem 2.4 Square graph of path $\mathrm{P}_{\mathrm{m}}$ is a linear incidence edge prime graph.

Proof: Let $G \rightarrow$ be the di graph and $\mathrm{u}_{1}, \mathrm{u}_{2}, \ldots, \mathrm{u}_{\mathrm{m}}$ are the vertices of $G^{\rightarrow}$.

Here $\left|\mathrm{V}\left(G^{\rightarrow}\right)\right|=\mathrm{m}$ and $\left|\mathrm{E}\left(G^{\rightarrow}\right)\right|=2 \mathrm{~m}-3$.

Define a relation $\mathrm{g}: \mathrm{V} \rightarrow\{0,1,2, \ldots, \mathrm{m}-1\}$ by

$$
g\left(u_{j}\right) \quad=j-1, \quad j=1,2, \ldots, m .
$$

It is evident from the definition that $\mathrm{g}$ is a $1-1$ and onto mapping. The edge labeling $g_{\text {liepl }}^{*}$ is defined as follows:

$$
\begin{array}{lll}
g_{\text {liepl }}^{*}\left(u_{j} u_{j+1}\right) & =3 \mathrm{j}-1, & \mathrm{j}=1,2, \ldots, \mathrm{m}-1 . \\
g_{\text {liepl }}^{*}\left(u_{j} u_{j+2}\right) & =3 \mathrm{j}+1, & \mathrm{j}=1,2, \ldots, \mathrm{m}-2 .
\end{array}
$$

Clearly $g_{\text {liepl }}^{*}$ is an injection. gcin of $\left(\mathrm{u}_{\mathrm{j}+2}\right)$

$$
\begin{aligned}
& =\operatorname{gcd} \text { of }\left\{g_{\text {liepl }}^{*}\left(u_{j} u_{j+2}\right), g_{\text {liepl }}^{*}\left(u_{j+1} u_{j+2}\right)\right\} \\
& =\operatorname{gcd} \text { of }\{3 \mathrm{j}+1,3 \mathrm{j}+2\} \\
& =1, \quad \mathrm{j}=1,2, \ldots, \mathrm{m}-2 .
\end{aligned}
$$

Hence $\left(\mathrm{P}_{\mathrm{m}}\right)^{2}$, is a linear incidence edge prime graph.

Theorem 2.5 Tortoise graph of path $\mathrm{P}_{\mathrm{m}}(\mathrm{m}>3)$ is a linear incidence edge prime graph.

Proof: Let $G \rightarrow$ be the di graph and $\mathrm{u}_{1}, \mathrm{u}_{2}, \ldots, \mathrm{u}_{\mathrm{m}}$ are the vertices of $G^{\rightarrow}$.

Here $\left|\mathrm{V}\left(G^{\rightarrow}\right)\right|=\mathrm{m}$ and $\left|\mathrm{E}\left(G^{\rightarrow}\right)\right|=\frac{3 m-3}{2}$.

Define a relation $\mathrm{g}: \mathrm{V} \rightarrow\{0,1,2, \ldots, \mathrm{m}-1\}$ by

$$
\mathrm{g}\left(\mathrm{u}_{\mathrm{j}}\right) \quad \mathrm{j}-1, \quad \mathrm{i}=1,2, \ldots, \mathrm{m} .
$$

It is evident from the definition that $\mathrm{g}$ is a $1-1$ onto mapping.

The edge labeling $g_{\text {liepl }}^{*}$ is defined as follows: 


$$
\begin{aligned}
& g_{\text {liepl }}^{*}\left(u_{2 j-1} u_{2 j}\right) \quad=6 \mathrm{j}-4, \quad \mathrm{j}=1,2, \ldots, \frac{m-1}{2}, \text { if } \mathrm{m} \text { is odd. } \\
& \mathrm{j}=1,2, \ldots, \frac{m-2}{2} \text {, if } m \text { is even. } \\
& g_{\text {liepl }}^{*}\left(u_{2 j-1} u_{2 j+1}\right) \quad=6 \mathrm{j}-2, \quad \mathrm{j}=1,2, \ldots, \frac{m-1}{2}, \text { if } \mathrm{m} \text { is odd. } \\
& j=1,2, \ldots, \frac{m-2}{2} \text {, if } m \text { is even. } \\
& g_{\text {liepl }}^{*}\left(u_{2 i} u_{2 i+2}\right) \quad=6 \mathrm{j}+1, \quad \mathrm{j}=1,2, \ldots, \frac{m-3}{2} \text {, if } \mathrm{m} \text { is odd. } \\
& j=1,2, \ldots, \frac{m-2}{2} \text {, if } m \text { is even. } \\
& g_{\text {liepl }}^{*}\left(u_{m-1} u_{m}\right) \quad=3 \mathrm{~m}-4 .
\end{aligned}
$$

Clearly $g_{\text {liepl }}^{*}$ is one-one.

$$
\begin{aligned}
\operatorname{gcin} \text { of }\left(\mathrm{u}_{2 j+2}\right) \quad & \operatorname{gcd} \text { of }\left\{g_{\text {liepl }}^{*}\left(u_{2 j} u_{2 j+2}\right), g_{\text {liepl }}^{*}\left(u_{2 j+1} u_{2 j+2}\right)\right\} \\
& =\operatorname{gcd} \text { of }\{6 \mathrm{j}+1,6 \mathrm{j}+2\} \\
& =1, \quad \mathrm{j}=1,2, \ldots, \frac{m-3}{2}, \text { if } \mathrm{m} \text { is odd. } \\
& \mathrm{i}=1,2, \ldots, \frac{m-4}{2}, \text { if } \mathrm{m} \text { is even. } \\
\operatorname{gcin} \text { of }\left(\mathrm{u}_{\mathrm{n}}\right) \quad & \operatorname{gcd} \text { of }\left\{g_{\text {liepl }}^{*}\left(u_{m-2} u_{m}\right), g_{\text {liepl }}^{*}\left(u_{m-1} u_{m}\right)\right\} \\
& =\operatorname{gcd} \text { of }\{3 \mathrm{~m}-5,3 \mathrm{~m}-4\} \\
& =1 .
\end{aligned}
$$

Hence $\operatorname{Tot}\left(\mathrm{P}_{\mathrm{n}}\right)$ is a linear incidence edge prime graph.

Theorem 2.6 Let $\mathrm{G}$ is the graph obtained by joining the corresponding internal vertices of two copies of path $\mathrm{P}_{\mathrm{m}}(\mathrm{m}>3)$ by edges. Di graph of $\mathrm{G}$ is a linear incidence edge prime graph.

Proof: Let $G \rightarrow$ be the di graph and $\mathrm{u}_{1}, \mathrm{u}_{2}, \ldots, \mathrm{u}_{2 \mathrm{~m}}$ are the vertices of $G^{\rightarrow}$.

Here $\left|\mathrm{V}\left(G^{\rightarrow}\right)\right|=2 \mathrm{~m}$ and $\left|\mathrm{E}\left(G^{\rightarrow}\right)\right|=3 \mathrm{~m}-4$.

Define a relation $\mathrm{g}: \mathrm{V} \rightarrow\{1,2, \ldots, 2 \mathrm{~m}-1\}$ by

$$
g\left(u_{j}\right) \quad=j-1, \quad j=1,2, \ldots, 2 \mathrm{~m} .
$$

It is evident from the definition that $\mathrm{g}$ is a $1-1$, onto mapping. 
The edge labeling $g_{\text {liepl }}^{*}$ is defined as follows:

$$
\begin{array}{ll}
g_{\text {liepl }}^{*}\left(u_{2 j-1} u_{2 j+1}\right) & \mathrm{j}=1,2, \ldots, \mathrm{m}-1 . \\
g_{\text {liepl }}^{*}\left(u_{2 j} u_{2 j+2}\right)=6 \mathrm{j}+1, & \mathrm{j}=1,2, \ldots, \mathrm{m}-1 . \\
g_{\text {liepl }}^{*}\left(u_{2 j+1} u_{2 j+2}\right) & \mathrm{j}=1,2, \ldots, \mathrm{m}-2 .
\end{array}
$$

Clearly $g_{\text {liepl }}^{*}$ is a one-one mapping.

$$
\begin{aligned}
\operatorname{gcin} \text { of }\left(\mathrm{u}_{2 \mathrm{j}+2}\right) & =\operatorname{gcd} \text { of }\left\{g_{\text {liepl }}^{*}\left(u_{2 j} u_{2 j+2}\right), g_{\text {liepl }}^{*}\left(u_{2 j+1} u_{2 j+2}\right)\right\} \\
& =\operatorname{gcd} \text { of }\{6 \mathrm{j}+1,6 \mathrm{j}+2\} \\
& =1, \quad \mathrm{i}=1,2, \ldots, \mathrm{n}-2 .
\end{aligned}
$$

Hence $\mathrm{G}$ is a linear incidence edge prime graph.

Theorem 2.7 Direct strong Z-graph of path $\mathrm{P}_{\mathrm{m}}(\mathrm{m}>2)$ is a linear incidence edge prime graph.

Proof: Let $G^{\rightarrow}$ be the di graph and $\mathrm{u}_{1}, \mathrm{u}_{2}, \ldots, \mathrm{u}_{2 \mathrm{~m}}$ are the vertices of $G^{\rightarrow}$.

Here $\left|\mathrm{V}\left(G^{\rightarrow}\right)\right|=2 \mathrm{~m}$ and $\left|\mathrm{E}\left(G^{\rightarrow}\right)\right|=4 \mathrm{~m}-3$.

Define a relation $\mathrm{g}: \mathrm{V} \rightarrow\{0,1,2, \ldots, 2 \mathrm{~m}-1\}$ by

$$
g\left(u_{j}\right) \quad=j-1, \quad j=1,2, \ldots, 2 m .
$$

It is evident from the definition that $\mathrm{g}$ is a $1-1$, onto mapping.

The edge labeling $g_{\text {liepl }}^{*}$ is defined as follows:

$$
\begin{array}{lll}
g_{\text {liepl }}^{*}\left(u_{2 j-1} u_{2 j}\right) & =6 \mathrm{j}-4, & \mathrm{j}=1,2, \ldots, \mathrm{m} . \\
g_{\text {liepl }}^{*}\left(u_{2 j-1} u_{2 j+1}\right) & =6 \mathrm{j}-2, & \mathrm{j}=1,2, \ldots, \mathrm{m}-1 . \\
g_{\text {liepl }}^{*}\left(u_{2 j} u_{2 j+1}\right) & =6 \mathrm{j}-1 & \mathrm{j}=1,2, \ldots, \mathrm{m}-1 . \\
g_{\text {liepl }}^{*}\left(u_{2 j} u_{2 j+2}\right) & =6 \mathrm{j}+1 & \mathrm{j}=1,2, \ldots, \mathrm{m}-1 .
\end{array}
$$

Clearly $g_{\text {liepl }}^{*}$ is one - one mapping.

$$
\begin{aligned}
\operatorname{gcin} \text { of }\left(\mathrm{u}_{2 \mathrm{j}+1}\right) & =\operatorname{gcd} \text { of }\left\{g_{\text {liepl }}^{*}\left(u_{2 j-1} u_{2 j+1}\right), g_{\text {liepl }}^{*}\left(u_{2 j} u_{2 j+1}\right)\right\} \\
& =\operatorname{gcd} \text { of }\{6 \mathrm{j}-2,6 \mathrm{j}-1\} \\
& =1, \\
& =\operatorname{gcd} \text { of }\left\{g_{\text {liepl }}^{*}\left(u_{2 j} u_{2 j+2}\right), g_{\text {liepl }}^{*}\left(u_{2 j+1} u_{2 j+2}\right)\right\} \\
& =\operatorname{gcd} \text { of }\{6 \mathrm{j}+1,6 \mathrm{j}+2\} \quad \mathrm{j}=1,2, \ldots, \mathrm{m}-1 . \\
& =1, \quad\left(\mathrm{u}_{2 \mathrm{j}+2}\right) \quad
\end{aligned}
$$


Hence, $S\left\{Z\left(P_{n}\right)\right\}$ is a linear incidence edge prime (Figures 1-6).

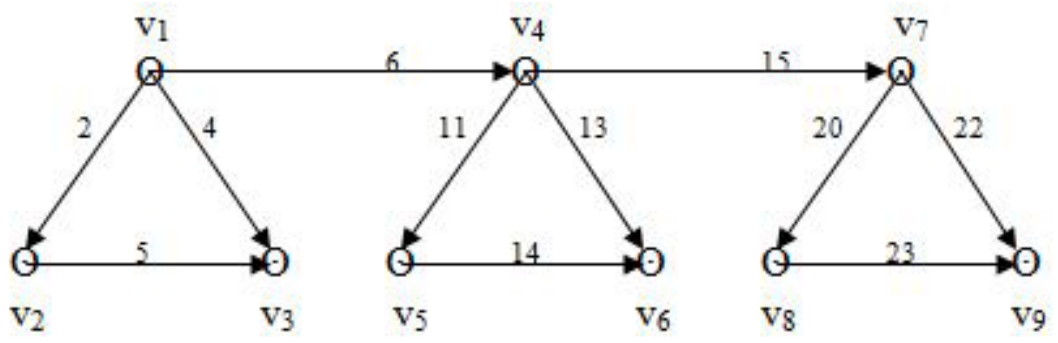

FIGURE 1. Linear incidence edge prime labeling of P3 $\theta \mathrm{K} 2$.

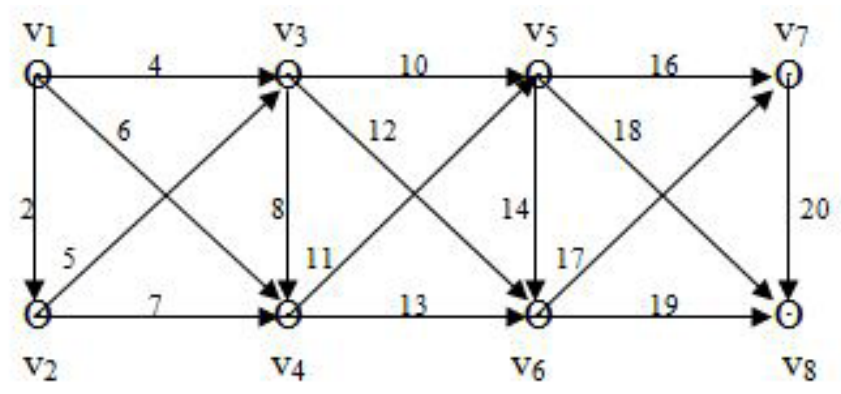

FIGURE 2. Linear incidence edge prime labeling of $S\{D 2(P 4)\}$.

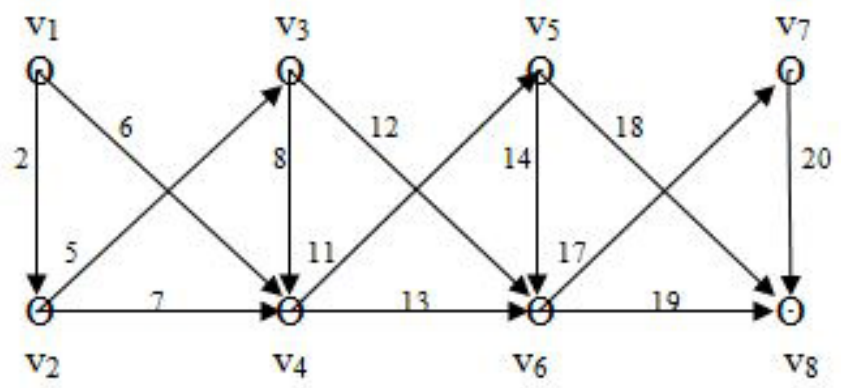

FIGURE 3. Linear incidence edge prime labeling of $S\{S,(P 4)\}$.

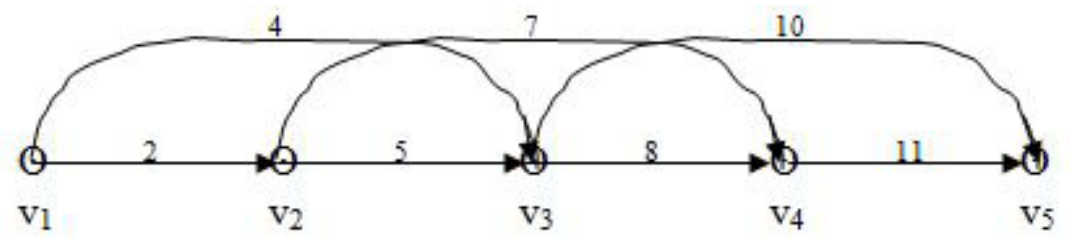

FIGURE 4. Linear incidence edge prime labeling of (P5)2. 


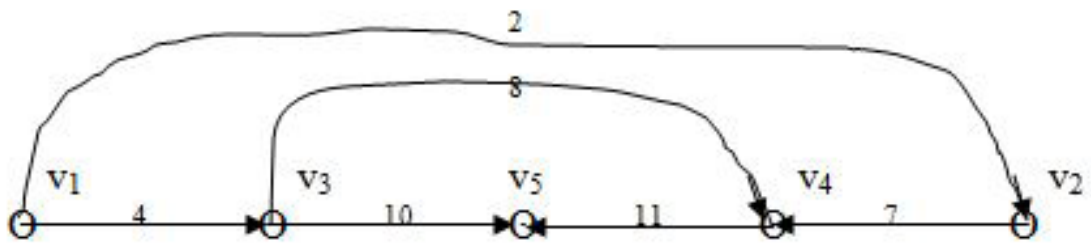

FIGURE 5. Linear incidence edge prime labeling of Tot(P5).

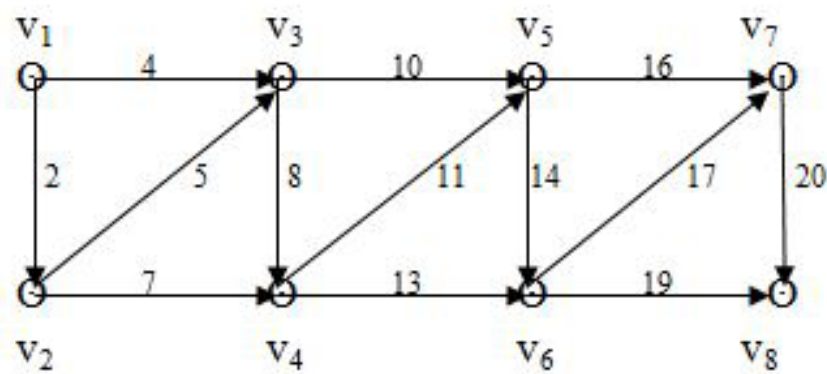

FIGURE 6. Linear incidence edge prime labeling of $S\{Z(P 4)\}$.

\section{Conclusion}

Here we established the fact that certain classes of path related di graphs are linear incidence edge prime graphs. Other researchers can find more graphs that admit linear incidence edge prime labeling.

\section{References}

1. Introduction to analytic number theory. https://www.amazon.in/Introduction-AnalyticNumber-Theory-Apostol/dp/8185015120. Date accessed: 1998.

2. Graph theory. https://cs.bme.hu/fcs/graphtheory.pdf. Date accessed: 2011.

3. Joseph A Gallian. A dynamic survey of graph labeling. The Electronic Journal of Combinatorics. 2018; 1-502.

4. Dhanalakshmi S, Parvathi N. Prime labeling of rough approximations for some special graphs. Indian Journal of Science and Technology. 2017; 10(25), 1-5.

5. Samal R, Mishra D. More results on polygonal sum labeling of graphs. Indian Journal of Science and Technology. 2017; 10(26), 1-10.

6. Sunoj BS, Mathew Varkey TK. Linear prime labeling of some path related di graphs. Journal of Harmonized Research in Applied Sciences. 2018; 6(3), 213-216. 